\title{
Potencial de aumento da qualidade nutricional do feijão por melhoramento genético
}

\section{Potential for increasing the nutritional quality in common beans through plant breeding}

\author{
Nerinéia Dalfollo Ribeiro ${ }^{1}$
}

\begin{abstract}
Resumo
O objetivo dessa revisão foi abordar os principais resultados obtidos pela pesquisa e as perspectivas para o aumento do teor de minerais (cálcio, ferro e zinco), de aminoácidos sulfurados (metionina e cisteína) e de fibra alimentar em feijão por melhoramento genético. Os caracteres que conferem qualidade nutricional ao feijão apresentam variação genética, efeito do ambiente e da interação genótipos $\mathrm{x}$ ambientes. Efeito materno foi observado na expressão do teor de cálcio, de ferro e de proteína em grãos de feijão e isso tem implicação direta na seleção e na condução das populações segregantes obtidas por programas de melhoramento. Estimativas elevadas de herdabilidade em sentido restrito foram observadas para cálcio, ferro e zinco, indicando facilidades para a seleção. O aumento dos teores de minerais, aminoácidos e fibra alimentar é possível por melhoramento genético. A disponibilização de germoplasma de feijão com melhor qualidade nutricional é importante para a nutrição humana e para a produção agrícola.
\end{abstract}

Palavras-chave: Phaseolus vulgaris L, variabilidade, efeito materno, herdabilidade, seleção

\begin{abstract}
The objective of this review was to mention the main results of research and the perspectives to increase minerals (calcium, iron and zinc), sulfur amino acids (methionine and cystine) and dietary fiber content in common beans by genetic breeding. The traits that show nutritional quality to common beans have genetic variability, environment and genotype $\mathrm{x}$ environment interaction. Maternal effect was observed in the expression of calcium, iron and protein content in common beans and this has a direct effect in the selection and in the conduction of the segregant populations obtained by plant breeding programs. High estimates of heritability in narrow sense were gotten for calcium, iron and zinc content, presenting acceptance for selection. The increase of minerals, amino acids and dietary fiber content is possible for plant breeding. The common bean germoplasm availability with nutritional quality is very important to human nutrition and to agriculture.
\end{abstract}

Key words: Phaseolus vulgaris L, variability, maternal effect, heritability, selection

1 Prof ${ }^{a}$. Adjunto IV, Dr. Universidade Federal de Santa Maria, UFSM. E-mail: nerineia@pq.cnpq.br Recebido para publicação 24/06/09 Aprovado em 16/09/10 


\section{Introdução}

A busca por alimentos que possam suprir as carências nutricionais e protéicas, com qualidade e com baixo custo, é uma necessidade iminente. Isso porque, as deficiências minerais são comuns em países em desenvolvimento, que utilizam basicamente grãos de cereais e raízes de plantas na alimentação. Entretanto, países industrializados também têm registrado níveis expressivos de deficiências minerais, como consequência da utilização de uma dieta não balanceada. Estimase que, em nível mundial, 60 a $80 \%$ das pessoas apresentam deficiência de ferro, mais de 30\% são deficientes em zinco, 30\% são deficientes em iodo e cerca de $15 \%$ são deficientes em selênio (KENNEDY; NANTIEL; SHETTY, 2003).

Uma má alimentação, seja por razões econômicas, culturais ou religiosas, pode desencadear uma série de problemas de saúde, devido à deficiência de minerais e a baixa ingestão de proteína e de fibra. Isso porque a deficiência de cálcio provoca osteoporose (MIGLIORANZA et al., 2003), a de ferro causa anemia (CUNHA; CUNHA, 1998) e a de zinco prejudica o crescimento e o sistema imunológico (HAMBIDGE, 2000). A baixa ingestão de proteína na primeira infância pode induzir distúrbios irreversíveis e produzir transtornos no desenvolvimento corporal eintelectual(MARQUES; BORA, 2000). Além disso, o consumo de alimentos ricos em fibra alimentar é essencial para manter a saúde e para prevenir diversas doenças crônicodegenerativas não transmissíveis, como câncer, problemas cardiovasculares e de constipação intestinal, diabetes e obesidade (HUGHES, 1991; GEIL; ANDERSON, 1994; MOORE; PARK; TSUDA, 1998; COSTA, 2003).

Por isso, as estratégias de suplementação, de fortificação dos alimentos e de diversificação da dieta têm sido recomendadas para minimizar os problemas decorrentes da má nutrição. A biofortificação, que consiste no aumento da biodisponibilidade do teor de minerais em porções comestíveis das plantas, por meio de intervenção agronômica ou seleção (WHITE; BROADLEY, 2005), também constitui numa alternativa racional e eficiente. Assim, por melhoramento genético se obtém um produto de melhor qualidade nutricional que pode ser fornecido à população sem nenhum custo adicional e sem a necessidade de estímulo para o consumo. Também, não se espera que ocorram alterações na forma de preparo e nas características organolépticas do alimento.

O aumento do teor de minerais em grãos é benéfico para a nutrição humana e para a produção agrícola. Genótipos de feijão com alto teor de ferro nos grãos foram também aqueles que apresentaram alto teor de zinco e maior biodisponibilidade de ferro (WELCH et al., 2000). Além disso, quando o teor de minerais foi elevado nas sementes de feijão, verificou-se maior número de plântulas viáveis e vigorosas, as plantas foram mais resistentes às doenças e mais eficientes no uso da água (FROSSARD et al., 2000).

Nesse sentido, informações sobre os efeitos da interação genótipos x ambientes, da ocorrência de efeito materno, da ação gênica e da herdabilidade em sentido restrito são relevantes para que o programa de melhoramento possa desenvolver cultivares de feijão com melhor qualidade nutricional. Nessa revisão serão abordados os principais resultados obtidos pela pesquisa e as perspectivas para o aumento do teor de minerais (cálcio, ferro e zinco), de aminoácidos sulfurados (metionina e cisteína) e de fibra alimentar em feijão (Phaseolus vulgaris L.) por melhoramento genético.

\section{Variabilidade genética para os caracteres que conferem qualidade nutricional ao feijão}

Os alimentos de origem animal são fontes biodisponíveis de minerais (COSTA; LIBERATO, 2003). Entretanto, devido ao elevado custo, são inacessíveis a muitas pessoas. Nesse sentido, o consumo de feijão é benéfico para a saúde, pois apresenta elevado teor de minerais nos grãos 
(BARAMPAMA; SIMARD, 1993; BEEBE; em acessos avaliados no México, de 172 a 406 GONZALEZ; RENGIFO, 2000; GUZMÁN- mg Ca $100 \mathrm{~g}^{-1}$ de matéria seca (MS) (GUZMÁNMALDONADO; ACOSTA-GALLEGOS; MALDONADO; ACOSTA-GALLEGOS; PAREDES-LÓPEZ, 2000; MESQUITA et al., 2007; PAREDES-LÓPEZ, 2000) (Tabela 1). Quando RIBEIRO et al., 2008), podendo ser utilizado na comparado a outras leguminosas, o feijão tem 50\% prevenção de diversas deficiências minerais.

Os teores de minerais nos grãos de feijão apresentam variabilidade genética e maior amplitude de variação para o teor de cálcio $(\mathrm{Ca})$ foi observada

a mais de cálcio que o grão-de-bico e $100 \%$ a mais que a lentilha (SEBASTIÁ et al., 2001). Além disso, o cálcio presente nas vagens e nos grãos imaturos do feijão vagem é prontamente absorvido pelo ser humano (GRUSAK et al., 1996).

Tabela 1. Variabilidade genética, de acordo com vários autores, para os teores de minerais (cálcio, ferro e zinco) - em mg 100g-1 de matéria seca, de aminoácidos sulfurados (metionina e cisteína) - em g por $16 \mathrm{~g}$ de $\mathrm{N}$ na matéria seca, e de fibra alimentar - em \%, em grãos de feijão.

\begin{tabular}{lcl}
\hline Constituinte & Valor & Referência \\
\hline Cálcio & 24 a 72 & BARAMPAMA; SIMARD (1993) \\
& 172 a 406 & GUZMÁN-MALDONADO; ACOSTA-GALLEGOS; PAREDES- \\
& 30 a 280 & LÓPEZ (2000) \\
\multirow{2}{*}{ Ferro } & 6,02 a 9,49 & BESQUITA et al. (2007) \\
& 7,14 a 12,69 & MESQUITA et al. (2007) \\
Zinco & 6,35 a 8,79 & BARAMPAMA; SIMARD (1993) \\
& 1,00 a 3,31 & GUZMÁN-MALDONADO; ACOSTA-GALLEGOS; PAREDES- \\
& 3,67 a 6,39 & MESEZ (2000) \\
Metionina & 0,64 a 1,26 & ABD EL-SAMEI; LÁSZTITY (1984) \\
& 1,13 a 1,42 & ANTUNES et al. (1995) \\
& 0,73 a 1,15 & RIBEIRO et al. (2007) \\
Cisteína & 1,07 a 1,57 & ABD EL-SAMEI; LÁSZTITY (1984) \\
& 1,11 a 1,51 & ANTUNES et al. (1995) \\
Fibra alimentar & 0,84 a 1,74 & RIBEIRO et al. (2007) \\
& 33,39 a 39,39 & LONDERO et al. (2006) \\
& 20,85 a 31,35 & LONDERO et al. (2008) \\
\hline
\end{tabular}

Diferenças genéticas também foram verificadas para o teor de ferro (Fe) e germoplasma com 12,69 mg Fe $100 \mathrm{~g}^{-1}$ de MS foi registrado no Brasil (MESQUITA et al., 2007). Beebe, Gonzalez e Rengifo (2000) constataram que há variabilidade genética suficiente para aumentar em $80 \%$ o teor de ferro nos grãos de feijão, após a avaliação de 1031 acessos cultivados e de 119 acessos silvestres de feijão do Banco de Germoplasma do Centro Internacional de Agricultura Tropical (CIAT), na Colômbia.
Valores altos de zinco ( $\mathrm{Zn}$ ) foram obtidos em germoplasma cultivado em Burundi, de 6,35 a 8,79 mg Zn $100 \mathrm{~g}^{-1}$ de MS (BARAMPAMA; SIMARD, 1993) (Tabela 1). Considerando a variabilidade genética disponível no Banco de Germoplasma de Feijão do CIAT, é possível aumentar em 50\% o teor de zinco em grãos de feijão (BEEBE; GONZALEZ; RENGIFO, 2000).

O feijão apresenta em sua constituição todos os aminoácidos essenciais, mas é deficiente em aminoácidos sulfurados - metionina e cisteína, por 
isso a sua proteína tem sido considerada de baixo valor biológico (ANTUNES et al., 1995; GUZMÁNMALDONADO; ACOSTA-GALLEGOS; PAREDES-LÓPEZ, 2000; MARQUES; BORA, 2000; PIRES et al., 2006). Entretanto, Ribeiro et al. (2007) observaram que algumas cultivares de feijão, disponíveis para o cultivo no Brasil, apresentaram teores de aminoácidos sulfurados superiores ao padrão considerado adequado pela Food and Agriculture Organization (FAO) para suprir as necessidades nutricionais diárias de um índivíduo adulto, que é de $1,7 \mathrm{~g}$ por $16 \mathrm{~g}$ de nitrogênio $(\mathrm{N})$ da MS para o somatório metionina + cisteína (FAO, 1998).

$\mathrm{O}$ teor de metionina variou de 0,73 a $1,15 \mathrm{~g}$ por $16 \mathrm{~g} \mathrm{~N}$ da MS e o teor de cisteína foi de $0,84 \mathrm{a}$ $1,74 \mathrm{~g}$ por $16 \mathrm{~g} \mathrm{~N}$ da MS em grãos de cultivares de feijão produzidas no Brasil (RIBEIRO et al., 2007) (Tabela 1). Portanto, espera-se eficiência na seleção de genótipos com melhor perfil de aminoácidos e a utilização de cultivares com melhor qualidade de proteína na alimentação.

Os grãos de feijão são ricos em fibra alimentar e apresentam a proporção de três partes de fibra insolúvel para uma parte de fibra solúvel (LONDERO et al., 2006; LONDERO et al., 2008). Os teores de fibra alimentar e das frações insolúvel e solúvel variam com as cultivares de feijão (BECKER et al., 1986; ACEVEDO; BRESSANI, 1990; CRUZ et al., 2004; LONDERO et al., 2005; LONDERO et al., 2006; LONDERO et al., 2008). Em grãos crús de cultivares e de linhagens segregantes de feijão desenvolvidas pelo melhoramento genético, o teor de fibra alimentar total (FA) variou de 33,39 a $39,39 \%$, sendo que a fibra insolúvel (FI) foi de 24,82 a $31,35 \%$ e a fibra solúvel (FS) de 8,04 a $11,11 \%$ (LONDERO et al., 2005; LONDERO et al., 2006).

Além disso, o feijão possui baixo teor de gordura e de sódio e não contém colesterol (HOSFIELD, 1991; MORROW, 1991). Por isso, o feijão é um alimento de alto valor nutricional, protéico e funcional e, como há variabilidade genética para os caracteres que conferem qualidade nutricional ao feijão, será possível selecionar germoplasma com alto valor nutritivo.

\section{Influência do ambiente e da interação genótipos $x$ ambientes nos caracteres que conferem qualidade nutricional ao feijão}

O ambiente pode contribuir para a alteração da composição de minerais, de aminoácidos e de fibra alimentar nos grãos de feijão. O acúmulo de ferro nos grãos de feijão é afetado pela acidez do solo, pois quando os grãos foram obtidos em solos ácidos $(\mathrm{pH} 6,0)$ apresentaram $25 \%$ a mais de ferro do que os grãos de solos alcalinos (pH 7,3) (MORAGHAN et al., 2002). O teor de zinco nos grãos de feijão também foi alterado pelo $\mathrm{pH}$ do solo e pela concentração de zinco no solo (CICHY et al., 2005).

Além disso, o teor de cálcio e de magnésio do solo terá efeito direto no tempo de cozimento dos grãos de feijão. Quando o cultivo foi realizado em solos com alto teor de cálcio e de magnésio e com temperatura média do ar mais elevada $\left(15\right.$ a $\left.24{ }^{\circ} \mathrm{C}\right)$, observou-se que os grãos de feijão necessitaram de mais tempo de cozimento para atingir a maciez considerada ideal para o consumo, em relação aos grãos obtidos de cultivo realizado em solos com baixos teores de magnésio e de fósforo e com temperatura média do ar mais baixa $\left(11\right.$ a $\left.18{ }^{\circ} \mathrm{C}\right)$ (PAREDES-LOPEZ et al., 1989).

Assim, alteração na composição química dos grãos de feijão pode ser esperada como resposta à localização geográfica, às condições edáficas (tipo de solo, $\mathrm{pH}$, fertilidade, textura, matéria orgânica, entre outros) e às variações climáticas (temperatura, precipitação, fotoperíodo, radiação, entre outros). Por isso, diferenças na composição de minerais, de aminoácidos e de fibra alimentar têm sido observadas em germoplasma de feijão quando cultivados em diferentes locais, anos e épocas de semeadura. 
Como resposta às diferenças no solo e às condições de ambiente, a composição química das cultivares de feijão se modifica nos locais de avaliação, ou seja, verifica-se a ocorrência da interação genótipos x ambientes. Por isso, interação cultivares x locais foi observada em Burundi para os teores de potássio $(\mathrm{K})$, cálcio, magnésio $(\mathrm{Mg})$, ferro, cobre $(\mathrm{Cu})$, zinco e fósforo $(\mathrm{P})$, em grãos de quatro cultivares de feijão, quando cultivados em quatro diferentes locais, no mesmo ano agrícola (BARAMPAMA; SIMARD, 1993). No Brasil, a avaliação de 19 cultivares de feijão, em dois municípios do Estado do Rio Grande do Sul (RS), possibilitou a constatação de efeito significativo da interação cultivares $\mathrm{x}$ locais para o teor de $\mathrm{Zn}$ (RIBEIRO et al., 2008). Interação genótipos $x$ locais foi verificada para o teor de ferro para 25 genótipos cultivados em três locais no Estado do Paraná (ARAÚJO et al., 2003).

Interações cultivares $\mathrm{x}$ locais significativas foram observadas para os teores de leucina, isoleucina, histidina, valina, treonina, glicina e alanina em grãos de cultivares de feijão cultivadas em dois municípios do RS (RIBEIRO et al., 2007). Interações cultivares $\mathrm{x}$ locais significativas também foram obtidas para os teores de fibra alimentar total, fibra insolúvel e fibra solúvel em grãos de 19 cultivares de feijão obtidas em dois ambientes (LONDERO et al., 2008).

Fatores genéticos, ambientais e da interação genótipos $\mathrm{x}$ ambientes afetam a acumulação de minerais, a composição de aminoácidos e as frações da fibra alimentar em grãos de feijão. Portanto, precisam ser avaliados pelo programa de melhoramento e a identificação de germoplasma com estabilidade para os caracteres da qualidade nutricional do feijão é de grande importância.

\section{Genética dos caracteres que conferem qualidade nutricional ao feijão}

O grão de feijão é composto pelo tegumento, que representa cerca de $9 \%$ na matéria seca (MS), cotilédones, com $90 \%$, e eixo embrionário, apenas $1 \%$ da MS (MESQUITA, 1989). Aproximadamente $67 \%$ a $81 \%$ do teor de cálcio em feijão estão presentes no tegumento dos grãos (MORAGHAN; ETCHEVERS; PADILHA, 2006). Entretanto, de 11 a $36 \%$ do ferro, de 7 a $12 \%$ do zinco e de 1,9 a $3,6 \%$ do fósforo se concentram no tegumento dos grãos de feijão (MORAGHAN et al., 2002). Como a acumulação dos minerais ocorre de maneira diferenciada no tegumento e nos cotilédones, a investigação de efeito materno na expressão dos teores de minerais em grãos de feijão se faz necessária. Isso porque tegumento é tecido materno e os cotilédones são produtos da fecundação, ou seja, são tecidos que estão presentes em gerações diferentes (RAMALHO; SANTOS; PINTO, 2000).

Jost et al. (2009b) observaram efeito materno na expressão do teor de cálcio em grãos de feijão, a partir dos cruzamentos realizados entre as cultivares Pérola x TPS Bonito e TPS Bonito x BRS Expedito. Nesse caso, os grãos $\mathrm{F}_{1}$ obtidos não representaram o produto da fecundação entre os genitores, pois os contrastes $\mathrm{P}_{1}$ versus $\mathrm{F}_{1}$ e $\mathrm{P}_{2}$ versus $\mathrm{F}_{1}$ recíproco não foram significativos e as médias das gerações $\mathrm{F}_{1}$ e $\mathrm{F}_{1}$ recíproco foram similares aos genitores femininos utilizados nos cruzamentos controlados (Figura 1). Na sequência, as médias das gerações $\mathrm{F}_{1}$ e $\mathrm{F}_{1}$ recíproco diferiram significativamente, comprovando que o fenótipo do descendente será dependente do genitor feminino e isso ocorre porque o teor de cálcio nos grãos de feijão depende do tegumento, que é tecido materno. Além disso, o movimento do cálcio entre o tegumento e o embrião (cotilédones e eixo embrionário) é restrito em feijão, provavelmente em função da presença de cristais de oxalato de cálcio insolúveis no tegumento de grãos maduros (MORAGHAN; ETCHEVERS; PADILHA, 2006). 
(1) Pérola x TPS Bonito

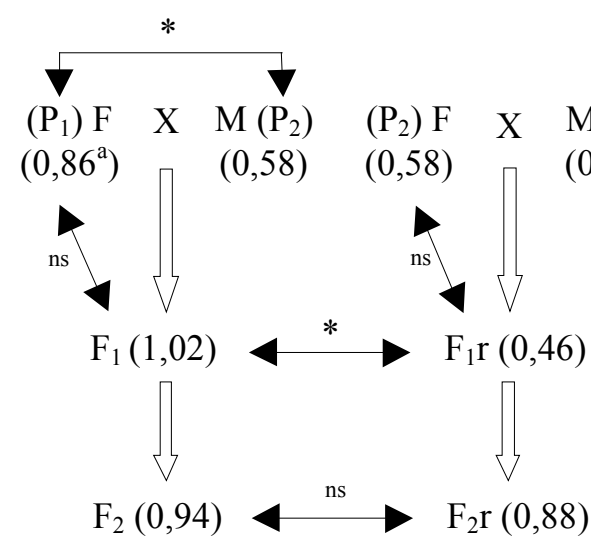

(2) TPS Bonito x BRS Expedito

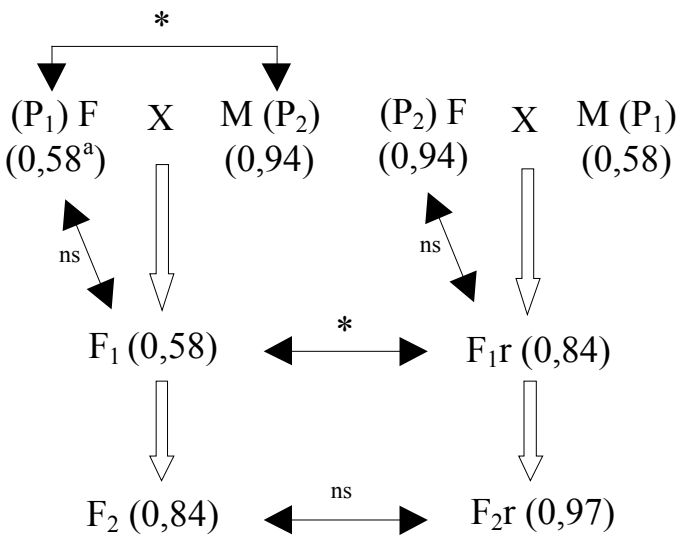

Figura 1. Genitores $\left(\mathrm{P}_{1}\right.$ e $\left.\mathrm{P}_{2}\right)$ e gerações $\mathrm{F}_{1} \mathrm{~F}_{1}$ recíproco $\left(\mathrm{F}_{1} \mathrm{r}\right), \mathrm{F}_{2}, \mathrm{~F}_{2}$ recíproco $\left(\mathrm{F}_{2} \mathrm{r}\right)$ com seus respectivos teores médios de cálcio nos grãos e teste de significância dos contrastes entre $\mathrm{P}_{1}$ versus $\mathrm{P}_{2}, \mathrm{P}_{1}$ versus $\mathrm{F}_{1}, \mathrm{P}_{2}$ versus $\mathrm{F}_{1}, \mathrm{~F}_{1}$ versus $\mathrm{F}_{1} \mathrm{r}$ $\mathrm{F}_{2}$ versus $\mathrm{F}_{2}$ r obtidos nos cruzamentos 1 (Pérola x TPS Bonito) e 2 (TPS Bonito x BRS Expedito). Santa Maria - RS, UFSM, 2007.

${ }^{\mathrm{a}}=$ Teor de cálcio $\left(\mathrm{g} \mathrm{kg}^{-1}\right.$ de MS); ${ }^{*}=$ Contraste significativo; ${ }^{\text {ns }}=$ Contraste não-significativo.

$\mathrm{F}=$ genitor feminino; $\mathrm{M}=$ genitor masculino.

Fonte: JOST et al. (2009b)

Efeito materno também foi constatado na expressão do teor de proteína (LELEJI et al., 1972) e de ferro (JOST et al., 2009a). Nesses casos, a expressão do genótipo da geração $\mathrm{F}_{1}$ somente será observada em grãos $\mathrm{F}_{2}$. Por conseguinte, em grãos $\mathrm{F}_{2}$, os cotilédones serão $\mathrm{F}_{1}$ e a seleção não é recomendada, pois será totalmente ineficaz. Por isso, a seleção deverá ser postergada para grãos $F_{3}$ (cotilédones em geração $\mathrm{F}_{2}$ ), quando segregação máxima será constatada nessa geração.

Para os teores de metionina e de cisteína (LONDERO et al., 2009a), de fibra solúvel e de fibra insolúvel em feijão (LONDERO et al., 2009b) não ocorre efeito materno significativo. Portanto, os grãos das gerações $\mathrm{F}_{1}$ e $\mathrm{F}_{1}$ recíproco representaram o produto da fecundação e, nesse caso, o embrião (cotilédones e eixo embrionário) caracteriza a geração $F_{1}$. Os grãos $F_{2}$ obtidos apresentaram embrião em geração $F_{2}$ e, por isso, a seleção para maior teor de aminoácidos sulfurados e de fibra alimentar deverá ser realizada em grãos da geração $\mathrm{F}_{2}$, que apresentará grande variabilidade genética. Isto posto, há inequívoca relevância na investigação da ocorrência de efeito materno para os caracteres que conferem qualidade nutricional ao feijão, pois terá implicações diretas na seleção e na condução de populações segregantes em programas de melhoramento.

A herdabilidade, em sentido amplo, do teor de cálcio foi determinada em vagens e em grãos imaturos de feijão e valores entre 48 a $50 \%$ foram obtidos (QUINTANA et al., 1999). Estimativas de herdabilidade em sentido restrito de moderada a alta foram constatadas para o teor de cálcio em grãos maduros de feijão: de $47,00 \%$ para a combinação Pérola x TPS Bonito e de $63,61 \%$ para a combinação TPS Bonito x BRS Expedito (JOST et al., 2009b). Quando a herdabilidade é moderada, ganhos seletivos são previstos se forem utilizados o Método Genealógico ou o Método Descendente de uma Única Semente (SSD). Entretanto, se a herdabilidade for alta, espera-se pouco efeito do ambiente sobre a expressão do caráter, que é governado por poucos genes e, por isso, as estratégias Bulk e o próprio SSD serão as mais adequadas para a capitalização de respostas seletivas dentre os segregantes obtidos. Além disso, como houve a predominância de variância aditiva na expressão do teor de cálcio, os 
ganhos seletivos dependerão apenas da variância gamética (CARVALHO et al., 2001; CRUZ, 2005).

Estimativas de herdabilidade, em sentido amplo, de alta magnitude $\left(\mathrm{h}^{2} \mathrm{a}: 76,36 \%\right)$ e em sentido restrito, de média magnitude $\left(\mathrm{h}^{2} \mathrm{r}: 50,60 \%\right)$ foram verificadas para o teor de ferro em grãos de feijão no cruzamento Minuano x Diamante Negro (JOST et al., 2009a). Nesse cruzamento, foi possível obter uma planta $\mathrm{F}_{2}$ com $16,12 \mathrm{mg} \mathrm{Fe} 100 \mathrm{~g}^{-1}$ da MS, representando um incremento de $94 \%$ do teor de ferro em grãos de feijão em relação ao genitor Minuano (8,28 mg Fe $100 \mathrm{~g}^{-1}$ da MS). Valor tão elevado de ferro só havia sido registrado em feijão silvestre e miúdo (GUZMÁN-MALDONADO; ACOSTA-GALLEGOS; PAREDES-LÓPEZ, 2000). Entretanto, como em plantas autógamas se observa alta heterozigose e heterogeneidade na geração $F_{2}$ e a heterose é reduzida a metade, a cada geração de autofecundação, não se espera que ocorra a fixação de um teor de ferro tão elevado em gerações mais avançadas.

Cichy et al. (2005) obtiveram herdabilidade em sentido amplo e restrito de $85 \%$ para o teor de zinco (Zn) em populações segregantes de feijão, obtidas a partir do cruzamento entre as cultivares Voyager x Albion. Além disso, o controle genético do teor de $\mathrm{Zn}$ nas sementes se dá por um único alelo dominante e a ação gênica aditiva foi responsável pela maior parte da variação do $\mathrm{Zn}$ nas sementes (SINGH; WESTERMANN, 2002; CICHY et al., 2005). Assim, considerando a herança monogênica dominante para o teor de $\mathrm{Zn}$ em feijão, esperamse facilidades para a seleção e para a transferência desse caráter pelos métodos de Retrocruzamentos, Genealógico, Descendente de uma Única Semente ou Seleção Gamética.

O teor de zinco nos grãos de feijão pode ser aumentado pelo melhoramento genético. Gelin et al. (2007) obtiveram gerações avançadas de feijão com teor de zinco superior aos genitores utilizados para o desenvolvimento das populações segregantes, evidenciando que segregação transgressiva pode ser observada em cruzamentos entre parentais contrastantes. Portanto, foi possível selecionar populações segregantes de feijão com maior teor de zinco nos grãos, que resultaram em plantas agronomicamente eficientes no uso do zinco e em grãos com melhor fonte de Zn para a nutrição humana (MORAGHAN; GRAFTON, 1999; HOUSE et al., 2002).

Além disso, a seleção de genótipos com alto teor de ferro nos grãos poderá ser efetiva também para o aumento no teor de zinco em feijão, pois esses dois minerais apresentaram correlação positiva (WELCH et al., 2000; GELIN et al., 2007). Moraghan et al. (2002) observaram que cultivares de feijão de grãos pretos apresentaram maior teor de ferro no tegumento dos grãos (35 a 40\%), enquanto que nas cultivares de grãos brancos, a concentração foi de 17 a $20 \%$ de ferro. Os autores atribuíram essa diferença ao teor de tanino, que é superior nas cultivares de grãos pretos. Taninos podem complexar ferro.

Correlações positivas entre $\mathrm{Zn}$ e $\mathrm{Ca}, \mathrm{Zn}$ e $\mathrm{P}, \mathrm{Fe}$ e P e Ca e P foram obtidas (GELIN et al., 2007). Como Beebe, Gonzalez e Rengifo (2000) também verificaram correlações positivas entre vários minerais em acessos de feijão de origem Andina e Mesoamericana, avaliados na Colômbia, espera-se que um alimento com maior valor nutritivo agregado possa ser obtido pelo melhoramento genético, pois a seleção será efetiva para dois ou mais minerais.

Herdabilidade, em sentido restrito, moderada foi obtida para metionina em feijão (KELLY; BLISS, 1975) e herdabilidade, em sentido amplo, de 97,03\% foi verificada para a fibra alimentar, no cruzamento entre BRS Valente $x$ Varre-Sai (LONDERO et al., 2006). Assim, ganhos com a seleção poderão ser esperados para os caracteres que conferem qualidade nutricional ao feijão, pois germoplasma com elevados teores de cálcio, de ferro, de zinco, de aminoácidos sulfurados e de fibra alimentar foram obtidos por melhoramento genético. 


\section{Perspectivas para o melhoramento qualidade nutricional do feijão}

Os teores de minerais, de aminoácidos e de fibra alimentar apresentam variabilidade genética e são afetados pelo ambiente e pela interação genótipos $\mathrm{x}$ ambientes. Por isso, a seleção de cultivares de feijão com maior qualidade nutricional deverá ser realizada após a avaliação em vários ambientes.

Efeito materno significativo foi observado para os teores de minerais (cálcio e ferro) e para o teor de proteína, por isso a seleção deverá ser realizada em grãos $\mathrm{F}_{3}$ (cotilédones em geração $\mathrm{F}_{2}$ ). Para os aminoácidos sulfurados (metionina e cisteína) e para a fibra alimentar (insolúvel e solúvel), recomenda-se que a seleção seja efetuada em grãos $\mathrm{F}_{2}$ (cotilédones em geração $\mathrm{F}_{2}$ ) devido à ausência de efeito materno Portanto, a geração dos cotilédones deverá ser considerada na condução das populações segregantes.

Estimativas elevadas de herdabilidade em sentido restrito e ação gênica aditiva foram observadas na expressão dos teores de minerais (cálcio, ferro e zinco), indicando facilidades para a seleção e para a transferência desses caracteres pelos métodos de Seleção Recorrente, Descendente de uma Única Semente e Genealógico.

Considerando o estado atual do conhecimento, acredita-se que o desenvolvimento de cultivares de feijão com melhor qualidade nutricional seja possível. A utilização dessas cultivares na alimentação, como parte integrante de uma dieta equilibrada, poderá contribuir para a melhora do estado de saúde, prevenindo ou minimizando diversas doenças crônicas não transmissíveis. Além disso, é preciso considerar que as cultivares biofortificadas ou nutracêuticas, obtidas por métodos clássicos de melhoramento, representarão um grande benefício social à população brasileira que tem o hábito de consumir feijão diariamente. A disponibilização de germoplasma com qualidade nutricional, agregada às características agronômicas de interesse, resultará em vantagens mercadológicas aos produtores rurais e na melhora da qualidade de vida dos consumidores.

\section{Agradecimentos}

Ao Conselho Nacional de Desenvolvimento Científico e Tecnológico (CNPq) pela bolsa concedida.

\section{Referências}

ABD EL-SAMEI, M. H.; LÁSZTITY, R. Comparative study on the amino acids composition in three local Phaseolus vulgaris seeds varieties. Zeitschrift für Lebensmitteluntersuchung und - Forschung A, Heidelberg, v. 178, n. 1, p. 24-26, 1984.

ACEVEDO, E.; BRESSANI, R. Contenido de fibra dietetica y digestibilidad del nitrogeno en alimentos centroamericanos: Guatemala. Archivos Latinoamericanos de Nutricion, Caracas, v. 40, n. 3, p. 439-451, 1990.

ANTUNES, P. L.; BIHALVA, A. B.; ELIAS, M. C.; SOARES, G. J. D. Valor nutricional de feijão (Phaseolus vulgaris, L.), cultivares Rico 23, Carioca, Piratã-1 e Rosinha-G2. Revista Brasileira de Agrociência, Pelotas, v. 1, n. 1, p. 12-18, 1995.

ARAÚJO, R.; MIGLIORANZA, E.; MONTALVAN, R.; DESTRO, D.; GONÇALVES-VIDIGAL, M. C.; MODA-CIRINO, V. Genotype x environment interation effects on the iron content of common bean grains. Crop Breeding and Applied Biotechnology, Londrina, v. 3, n. 4, p. 269-274, 2003.

BARAMPAMA, Z.; SIMARD, R. E. Nutrient composition, protein quality and antinutritional factors of some varieties of dry beans (Phaseolus vulgaris) grown in Burundi. Food Chemistry, Barking, v. 47, n. 2, p. 159167, 1993.

BECKER, H. G.; STELLER, W.; FELDHEIM, W.; WISKER, E.; KULIKOWSKI, W.; SUCKOW. P.; MEUSER, F.; SEIBEL, W. Dietary fiber and bread: intake, enrichment, determination and influence on colonic function. Cereal Foods World, Saint Paul, v. 31, n. 4, p. 306-310, 1986.

BEEBE, S.; GONZALEZ, A. V.; RENGIFO, J. Research on trace minerals in the common bean. Food and Nutrition Bulletin, Boston, v. 21, n. 4, p. 387-391, 2000.

CARVALHO, F. I. F. de; SILVA, S. A.; KUREK, A. J.; MARCHIORO, V. S. Estimativas e implicações da herdabilidade como estratégia de seleção. Pelotas: UFPEL, 2001. $98 \mathrm{p}$.

CICHY, K. A.; FORSTER, S.; GRAFTON, K. F.; HOSFIELD, G. L. Inheritance of seed zinc accumulation 
in navy bean. Crop Science, Madison, v. 45, n. 3, p. 864870, 2005.

COSTA, N. M. B. Alimentos: componentes nutricionais e funcionais. In: COSTA, N. M. B.; BORÉM, A. (Ed.). Biotecnologia e nutrição: saiba como o DNA pode enriquecer os alimentos. São Paulo: Nobel, 2003. Cap. 2, p. 32-69.

COSTA, N. M. B.; LIBERATO, S. C. Biotecnologia na nutrição e saúde. In: COSTA, N. M. B.; BORÉM, A. (Ed.). Biotecnologia e nutrição: saiba como o DNA pode enriquecer os alimentos. São Paulo: Nobel, 2003. Cap. 3, p. 71-127.

CRUZ, C. D. Princípios de genética quantitativa. Viçosa: UFV, 2005. 394 p.

CRUZ, G. A. D. R.; OLIVEIRA, M. G. A.; PIRES, C. V.; PILON, A. M.; CRUZ, R. S.; BRUMANO, M. H. N.; MOREIRA, M. A. Avaliação da digestibilidade protéica, inibidor de protease e fibras alimentares de cultivares de feijão (Phaseolus vulgaris L.). Brazilian Journal of Food Technology, Campinas, v. 7, n. 2, p. 103-109, 2004.

CUNHA, D. F.; CUNHA, S. F. C. Microminerais In: DUTRA-DE-OLIVEIRA, J. E.; MARCHINI, J. S. (Ed.). Ciências nutricionais. São Paulo: Sarvier, 1998. Cap. 9, p. 141-165.

FAO. Junta de Conselho de Especialistas FAO/WHO/ ONU. Necessidades de energia e proteína. São Paulo: Roca, 1998. 225 p.

FROSSARD, E.; BUCHER, M.; MACHLER, F.; MOZAFAR, A.; HURRELL, R. Potencial for increasing the content and bioavailability of $\mathrm{Fe}, \mathrm{Zn}$ and $\mathrm{Ca}$ in plants for human nutrition. Journal of the Science of Food and Agriculture, London, v. 80, n. 7, p. 861-879, 2000.

GEIL, P. B.; ANDERSON, J. W. Nutrition and health implications of dry beans: a review. Journal of the American College of Nutrition, Clearwater, v. 13, n. 6, p. 549-558, 1994.

GELIN, J. R.; FORSTER, S.; GRAFTON, K. F.; McCLEAN, P. E.; ROJAS-CIFUENTES, G. A. Analysis of seed zinc and other minerals in a recombinant inbred population of navy bean (Phaseolus vulgaris L.). Crop Science, Madison, v. 47, n. 4, p. 1361-1366, 2007.

GRUSAK, M. A.; PEZESHGI, S.; O'BRIEN, K. O.; ABRAMS, S. A. Intrinsic $42 \mathrm{Ca}$-Labelling of green bean pods for use in human biovailability studies. Journal of the Science of Food and Agriculture, Chichester, v. 70, n. 1, p. 11-15, 1996.

GUZMÁN-MALDONADO, S. H.; ACOSTAGALlEGOS, J.; PAREDES-LÓPEZ, O. Protein and mineral content of a novel collection of wild and weedy common bean (Phaseolus vulgaris L). Journal of the
Science of Food and Agriculture, London, v. 80, n. 13, p. 1874-1881, 2000.

HAMBIDGE, M. Human zinc deficiency. Journal of Nutrition, Bethesda, v. 130, n. 5, p. 1344-1349, 2000.

HOSFIELD, G. L. Genetic control of production and food quality factors in dry bean. Food Technology, Chicago, v. 45, n. 9, p. 98-103, 1991.

HOUSE, W. A.; WELCH, R. M.; BEEBE, S.; CHENG, Z. Potencial for increasing the amounts of bioavailable zinc in dry beans (Phaseolus vulgaris L.) through plant breeding. Journal of the Science of Food and Agriculture, London, v. 82, n. 13, p. 1452-1457, 2002.

HUGHES, J. S. Potential contribution of dry bean dietary fiber to health. Food Technology, Chicago, v. 45, n. 9, p. 122-126, 1991.

JOST, E.; RIBEIRO, N. D.; CERUTTI, T.; POERSCH, N. L.; MAZIEIRO, S. M. Potencial de aumento do teor de ferro em grãos de feijão por melhoramento genético. Bragantia, Campinas, v. 68, n. 1, p. 35-42, 2009a.

JOST, E.; RIBEIRO, N. D.; MAZIERO, S. M.; CERUTTI, T.; ROSA, D. P. Efeitos gênicos do teor de cálcio em grãos em feijão. Ciência Rural, Santa Maria, v. 39, n. 1, p. 31-37, 2009b.

KELLY, J. D.; BLISS, F. A. Heritability estimates of percentage seed protein and available methionine and correlations with yield in dry beans. Crop Science, Madison, v. 15, n. 6, p. 753-757, 1975.

KENNEDY, G.; NANTEL, G.; SHETTY, P. The scourge of "hidden hunger": global dimensions of micronutrient deficiencies. Food Nutritional Agriculture, Roma, v. 32, p. 8-16, 2003.

LELEJI, O. I.; DICKSON, M. H.; CROWDER, L. V.; BOURKE, J. B. Inheritance of crude protein percentage and its correlation with seed yield in beans, Phaseolus vulgaris L. Crop Science, Madison, v. 12, n. 2, p. 168171, 1972.

LONDERO, P. M. G.; RIBEIRO, N. D.; CARGNELUTTI FILHO, A.; RODRIGUES, J. A.; ANTUNES, I. F. Herança dos teores de fibra alimentar e rendimento de grãos em populações de feijoeiro. Pesquisa Agropecuária Brasileira, Brasília, v. 41, n. 1, p. 51-58, 2006.

LONDERO, P. M. G.; RIBEIRO, N. D.; CERUTTI, T.; MAZIERO, S. M.; ROSA, D. P.; ROSA, S. S. Efeito materno na expressão dos teores de aminoácidos sulfurados em grãos de feijão. Ciência Rural, Santa Maria, v. 39, n. 6, p. 1884-1887, 2009a.

LONDERO, P. M. G.; RIBEIRO, N. D.; JOST, E.; MAZIERO, S. M.; CERUTTI, T.; POERSCH, N. L. Genética dos teores de fibras insolúvel e solúvel em 
grãos de feijão. Revista Ceres, Viçosa, MG, v. 56, n. 2, p. 150-155, 2009b.

LONDERO, P. M. G.; RIBEIRO, N. D.; POERSCH, N. L.; ANTUNES, I. F.; NORNBERG, J. L. Análise de frações de fibra alimentar em cultivares de feijão cultivadas em dois ambientes. Ciência Rural, Santa Maria, v. 38, n. 7, p. 2033-2036, 2008.

LONDERO, P. M. G.; RIBEIRO, N. D.; RODRIGUES, J. A.; POERSCH, N. L.; TRENTIN, M. Genetic variability for dietary fiber content in common bean populations. Crop Breeding and Applied Biotechnology, Viçosa, v. 5, n. 1, p. 86-90, 2005.

MARQUES, M. F.; BORA, P. S. Composición química y análisis de aminoácidos de alubias. Ciencia y Tecnología Alimentaria, Reynosa, v. 2, n. 5, p. 248-252, 2000.

MESQUiTA, F. R.; CORRÊA, A. D.; ABREU, C. M. P.; LIMA, R. A. Z.; ABREU, A. F. B. Linhagens de feijão (Phaseolus vulgaris L.): composição química e digestibilidade protéica. Ciência e Agrotecnologia, Lavras, v. 31, n. 4, p. 1114-1121, 2007.

MESQUITA, L. A. Efeito materno na determinação do tamanho da semente do feijoeiro (Phaseolus vulgaris L.). 1989. Dissertação (Mestrado em Genética e Melhoramento de Plantas) - Programa de Pós-Graduação em Genética e Melhoramento de Plantas. Universidade Federal de Lavras, Lavras.

MIGLIORANZA, E.; ARAÚJO, R. de; ENDO, R. M.; SOUZA, J. R. P. de.; MONTANARI, M. A. Teor de cálcio em frutos de diferentes cultivares de feijão-vagem. Horticultura Brasileira, Brasília, v. 21, n. 2, p. 158-161, 2003.

MOORE, M. A.; PARK, C. B.; TSUDA, H. Soluble and insoluble fiber influences on cancer development. Critical Reviews in Oncology/Hematology, New York, v. 27, n. 3, p. 229-242, 1998.

MORAGHAN, J. T.; ETCHEVERS, J. D.; PADILHA, J. Contrating accumulations of calcium and magnesium in seed coats and embryos of common bean and soybean. Food Chemistry, London, v. 95, n. 4, p. 554-561, 2006.

MORAGHAN, J. T.; GRAFTON, K. Seed-zinc concentration and the zinc-efficiency trait in navy bean. Soil Science Society of America Journal, Madison, v. 63, n. 4, p. 918-922, 1999.

MORAGHAN, J. T.; PADILHA, J.; ETCHEVERS, J. D.; GRAFTON, K.; ACOSTA-GALLEGOS, J. A. Iron accumulation in seed of common bean. Plant and Soil, Dordrecht, v. 246, n. 2, p. 175-183, 2002.
MORROW, B. The rebirth of legumes. Food Technology, Chicago, v. 45, n. 9, p. 96-121, 1991.

PAREDES-LOPES, O.; REYES-MORENO, C.; MONTES-RIVEIRA, R.; CARAHEZ-TREJO, A. Hardto-cook phenomenon in common beans: influence of growing location and hardening procedures. International Journal of Food Science and Techonology, New York, v. 24, n. 5, p. 535-542, 1989.

PIRES, C. V.; OLIVEIRA, M. G. A.; ROSA, J. C.; COSTA, N. M. B. Qualidade nutricional e escore químico de aminoácidos de diferentes fontes protéicas. Ciência e Tecnologia dos Alimentos, Campinas, v. 26, n. 1, p. 179187, 2006.

QUINTANA, J. M.; HARRISON, H. C.; NIENHUIS, J.; PALTA, J. P.; KMIECILK, K. Comparison of pod calcium concentration between two snap bean populations. Journal of the American Society for Horticultural Science, Alexandria, v. 124, n. 3, p. 273-276, 1999.

RAMALHO, M. A. P.; SANTOS, J. B. dos; PINTO, C. A. B. Genética na agropecuária. Lavras: UFLA, 2000. $472 \mathrm{p}$.

RIBEIRO, N. D.; JOST, E.; CERUTTI, T.; MAZIERO, S. M.; POERSCH, N. L. Composição de microminerais em cultivares de feijão e aplicações para o melhoramento genético. Bragantia, Campinas, v. 67, n. 2, p. 267-273, 2008.

RIBEIRO, N. D.; LONDERO, P. M. G.; CARGNELUTTI FILHO, A.; JOST, E.; POERSCH, N. L.; MALLMANN, C. A. Composição de aminoácidos de cultivares de feijão e aplicações para o melhoramento genético. Pesquisa Agropecuária Brasileira, Brasília, v. 42, n. 10, p. 1393 1399, 2007.

SEBASTIÁ, V.;BARBERÁ, R.;FARRÉ, R.; LAGARDA, M. J. Effects of legume processing on calcium, iron and zinc contents and dialysabilities. Journal of the Science of Food and Agriculture, Sussex, v. 81, n. 12, p. 11801185, 2001.

SINGH, S. P.; WESTERMANN, D. T. A single dominant gene controlling resistance to soil zinc deficiency in common bean. Crop Science, Madison, v. 42, n. 4, p. 1071-1074, 2002.

WELCH, R. M.; HOUSE, W. A.; BEEBE, S.; CHENG, $Z$. Genetic selection for enhanced biovailable levels of iron in bean (Phaseolus vulgaris L.) seeds. Journal of Agricultural Food Chemistry, Chicago, v. 48, n. 8, p. 3576-3580, 2000.

WHITE, P. J.; BROADLEY, M. R. Biofortifying crops with essencial mineral elements. Trends in Plant Science, Oxford, v. 10, n. 12, p. 586-593, 2005. 